\title{
Benjamin Franklin: uma vida americana
}

\section{Benjamin Franklin: an american life}

Guilherme Tadeu de Paula*

ISAACSON, Walter. Benjamin Franklin: uma vida americana. Tradução de Pedro Maia Soares - $1^{\mathrm{a}}$ edição - São Paulo: Companhia das Letras, 2015. 585 p.

A publicação no final de 2015 da tradução para o português da biografia de Benjamin Franklin pela Companhia das Letras, de Walter Isaacson, é uma curiosa expressão do atual estado da arte do mercado cultural de nosso tempo. Como numa síntese alegórica, se reúnem para materializar-se em um formato acabado de uma grande peça publicitária para ser comercializada nas prateleiras de grandes livrarias nacionais bem como em suas diversas plataformas virtuais em suas versões eletrônicas, o mainstream da produção ideológica que vigora em nosso tempo - e que resiste e se transforma sem perder o controle do manche.

* Doutorando em História pela Universidade Estadual de Maringá, Paraná, Brasil. Email: guilhermetadeudepaula@gmail.com 
A começar pelo biografado, Benjamin Franklin, o homem não-europeu mais famoso na Europa no período que antecedeu e experimentou as grandes revoluções que transformariam o mundo. Antes de um pensador e ativista político de relevo, Franklin foi um grande editor - sem dúvida o mais relevante do século XVIII e, como um Midas da indústria gráfica, fez fortuna e ergueu um império na produção e circulação de livros, jornais, almanaques, sendo um dos empresários mais influentes e prósperos da época colonial pré-estadunidense.

No entanto, parece oportuno afirmar que Franklin pertence a outro tempo: é anacronismo dar aos Estados Unidos a importância que hoje estes experimentam no cenário internacional de potência cultural, política e militar de destaque. Foi a série de acontecimentos nos séculos posteriores à sua atuação destacada nos negócios públicos que deu à nação por ele "fundada" o estatuto de relevância incontestável para os rumos daquilo que geralmente consideramos, sem muito critério, a grande história universal.

São os intelectuais de cada era que vão dar sentido e significado a trajetória de seus antepassados, situando e problematizando os heróis e os símbolos de cada época, buscando realçar características "perdidas" e "atualizar" seus pensamentos e suas práticas pensando-os não como homens em seu tempo - mas como referências dotadas de certo grau de universalidade - não somente espacial e/ou cultural, mas mesmo na improvável dimensão da passagem do tempo. Tanto a esquerda como a direita têm seus heróis cujas percepções e reflexões ultrapassaram a dimensão do próprio debate que se inseriu e se tornaram paradigmas intocáveis.

No caso dos Estados Unidos, o mito dos pais-fundadores ocupa um lugar central na formulação de uma autoimagem idealizada de seu passado. $\mathrm{O}$ resultado deste processo é um peculiar desarranjo cuja coerência é facilmente superada pelo oportunismo: não raras vezes encontramos frases atribuídas aos homens de ação do século XVIII soltas e destituídas de qualquer contextualização em discursos políticos das figuras mais diversas - e inúmeras vezes, abastecendo ideias que em nada se aproximavam ao interesse original de seu formulador. De qualquer maneira, é um processo que se sustenta justamente porque a trajetória daquelas figuras ocupa um espaço intocável de virtude e sabedoria. Citá-los vale menos pelo conteúdo do que pelo próprio ato de referenciar seu argumento por alguma figura heroica. É como se o passado memorável e intocável referendasse o interesse agora em disputa.

Por isso, quando tomamos contato com a biografia de Benjamin Franklin de Walter Isaacson publicada em 2003 e que chega agora ao Brasil com a tradução de Pedro Maia Soares em 2015, é importante situá-la não simplesmente como uma nova narrativa sobre uma das trajetórias pessoais mais interessantes de todos os tempos. Ela é, também, um discurso, uma expressão de um projeto político e ideológico particularmente interessado - senão especificamente no varejo das disputas ideológicas, mas em um sentido amplo, como militância 
honesta mas não por isso menos perniciosa, por uma causa específica: trata-se de um hino ao capitalismo meritocrático do self-made man.

Jornalista especializado em política internacional desde a década de 1970, Walter Isaacson havia escrito dois livros antes da biografia de Benjamin Franklin, ambos de alguma maneira dedicados à diplomacia estadunidense do século XX: em 1986, em parceria com Evan Thomas, publicou The Wise Men: Six Friends and the World They Made, que conta as minúcias do processo que criou a OTAN, o Plano Marshall e o Banco Mundial na década de 1940. Seis anos mais tarde, foi responsável pela biografia de Henry Kissinger, um dos mais relevantes dirigentes e articuladores políticos dos Estados Unidos do século XX. Dedicar-se a biografar Franklin fazia sentido para essa trajetória: o paifundador é considerado, ainda hoje, o embaixador mais brilhante da história daquele país - e a narração que Isaacson faz do modo como este conduziu os complexos e intrincados interesses tanto na França como na Inglaterra são parte importante da obra que agora o público brasileiro tem acesso.

Sua trajetória posterior à publicação da biografia de Franklin, porém, diz mais ainda sobre o tipo de leitura que Isaacson fez de Franklin. Sua carreira no jornalismo político, consolidada como editor-chefe da Time Magazine, chegou ao auge em 2001 quando se tornou presidente e CEO da CNN. Em 2004, uma mudança de rumos: se tornou presidente do Aspen Institute, um dos mais relevantes e influentes think tank dos Estados Unidos. Desde então, sua atuação tem sido como um agente político institucional, associando a diversos projetos, sejam estes de iniciativa governamentais ou não, nas mais diferentes áreas de interesse.

A partir desta nova posição, Isaacson publicou mais quatro livros: em 2007, biografou a vida de outro cientista, Einsten - sua primeira obra publicada no Brasil, dois anos depois, pela Companhia das Letras. Em 2009, lançou uma coletânea de ensaios biográficos, o American Sketches, com narrativas sobre personagens que ele considerou fundamentais para a construção dos Estados Unidos: entre eles, estavam Franklin, Einsten, Bill Gates, Woody Alen, Reagan, os Clinton, entre outros. Em 2011, publicou o seu trabalho mais famoso: a biografia autorizada de Steve Jobs, best-seller publicado no Brasil no mesmo ano e que em 2015 Hollywood transformou em filme. Por fim, seu mais novo trabalho, de 2014, trata-se de um longo ensaio histórico sobre a revolução digital: “Os inovadores: uma biografia da revolução digital”, também publicado pela editora paulista. Cabe ainda mencionar que a Companhia das Letras transformou em outro livro de Isaacson um artigo que este escreveu para a Harvard Business Review, o "The Real Leadership Lessons of Steve Jobs" no qual este relata algumas passagens do processo de produção da biografia e da convivência com o biografado.

É interessante notar, portanto, que a publicação para o Brasil da biografia de Benjamin Franklin em 2015 se dá depois de quatro livros de Isaacson terem 
sido lançados - e todos eles, posteriores em seu lançamento ao original. Neste sentido, não parece exagero dizer que se observarmos de onde e como a obra se apresenta e pelo próprio aspecto de dialogar com e se propor para um público que mais está em busca do empreendedorismo e das lições de negócio dos homens de sucesso, o Franklin de Isaacson é o primeiro yuppie - ou, o youppie fundador (p.489). Esta é uma expressão que o biógrafo reivindica de David Brooks em um dos momentos de síntese analítica mais sincera e expressiva da obra: ele é a única figura histórica do panteão americano, segundo Brooks, 'que se sentiria imediatamente à vontade em um parque empresarial'"' (p.488).

O Benjamin Franklin que chega ao Brasil, um país cuja historiografia sobre os Estados Unidos oscila entre o desinteresse absoluto e a justa crítica anti-imperialista e que na mesma proporção que produz uma série de relevantes trabalhos sobre a potência bélica e militar do século XX e XXI, basicamente ignora todo o seu passado colonial e revolucionário, chega pelas mãos do biógrafo de Steve Jobs, como a própria capa do livro avisa.

Walter Isaacson não chega a ser leviano, mas é, no mínimo, complacente com uma série de dubiedades no caráter de Benjamin Franklin. A mais grave é relativizar e, em certo sentido, até enaltecer, sua propensão aos arranjos com a máquina pública. Isso ocorreu em todos os níveis, desde nos estágios mais primitivos de organização política colonial da Pensilvânia quando empreende seus primeiros contratos lucrativos de prestação de serviço a partir de sua gráfica até em larga escala, tendo ocupado a posição de agente de correios nas colônias a mando do rei. Tais operações são tratadas como arrojos de um empresário audaz e oportunista, no sentido positivo que esta palavra traz. Isaacson busca no receituário do personagem mais famoso de Franklin o caráter pretensamente legítimo desta prática: "No espírito do que o Pobre Ricardo chamaria de 'se dar bem fazendo o bem', Franklin não era avesso a misturar seus interesses particulares com os públicos" (p.70). Para além disso, Isaacson cita sem polemizar ou reconstruir a mitologia política que ronda a figura de Franklin, uma série de episódios que a política de nossa época certamente olharia com outros olhos: há inúmeros exemplos de nepotismo, circulação de boatos para destruição de adversários, promoção de interesses pessoais a partir de reflexões analíticas, filosóficas e políticas, mudanças de posição ao sabor das conjunturas sem perder jamais a associação com o poder, entre outros.

Pelo contrário, ao tentar tornar terrena a figura mitológica de um paifundador, é que o biógrafo transforma Benjamin Franklin em um símbolo insuperável. Ele se fez por conta própria, é repleto de maneirismos próprios a um mundo sem rodeios, e é, sobretudo, defectível. O autor marca nisso o seu traço distintivo com outras figuras célebres de seu período: "Os colegas de George Washington achavam difícil se imaginar tocando o austero general no ombro; hoje, nós acharíamos isso ainda mais difícil. Jefferson e Adams são igualmente intimidantes" (p.10) e sintetiza, em Franklin, a figura do americano 
realmente possível: "Franklin, aquele empresário urbano ambicioso, parece feito de carne em vez de mármore, possível de ser chamado pelo apelido; e no palco da história, ele se vira para nós com olhos que cintilam por trás daqueles óculos modernosos" (IDEM).

Essa a marca fundamental do Franklin de Isaacson: ele não era brilhante e erudito como Thomas Jefferson e John Adams. Seus textos e, sobretudo, a sua atuação política se erguiam numa prática equilibrista como um negociador incansável e implacável. Era, sobretudo, um homem de ação que soube usufruir das potencialidades que construiu como um imponente empresário gráfico para fazer suas ideias ecoarem. $\mathrm{Na}$ ciência, se repete o argumento: pouco interessado em questões teóricas, se destacava por sua astúcia e sua sensibilidade para compreender como os fenômenos aconteciam. Neste sentido, seu lugar na História da Ciência se dá mais pela sua curiosidade do que por seu conhecimento de gabinete. O biógrafo ressalta, não sem lamentar, que o pai-fundador teve mais fama e relevância em vida do que na posteridade, tanto como agente político e filósofo, tendo convivido e sendo tratado como par de nomes que se tornaram célebres na Filosofia Moderna como David Hume, Adam Smith e Voltaire, quanto como cientista, recebido com honras e glórias por toda a Europa por conta de suas descobertas no ramo da eletricidade que tiveram a inquestionável aplicabilidade prática de criar para-raios. Os relatos e detalhes destes contextos e das relações que a partir dele são construídas são o ponto alto desta obra e a frase de Turgot sua síntese saborosa: "Ele arrebatou o relâmpago do céu e o cetro dos tiranos" (p. 495).

Se a riqueza na narrativa das minúcias das negociações e nos arranjos de Franklin em meio aos múltiplos interesses que equilibrou ao longo da vida empolga tanto pelo talento do texto de Isaacson quanto por seu cuidado em projetar cenários e analisar o processo histórico com rigor, o excessivo destaque que ele dá para as relações íntimas do personagem analisado acaba por ser o elo mais fraco que constrói a figura biografada. Para além dos seus parentes mais próximos, como a esposa, filhos e netos, a biografia relata longamente as amizades femininas de Franklin - não sem a picardia que se espera de arranjos bastante incomuns mesmo para os dias atuais. $\mathrm{O}$ autor se esforça para não transformar a narração de tais atos em algo banal ou sem relevância perante o grande processo em que esses acontecimentos se inseriram, situando noções que aparecem nas cartas e nas práticas de Franklin como indicativos que podem ajudar a reconstruir a mentalidade do pai-fundador em relação a variados temas como a escravidão, as mulheres, a ostentação da riqueza, a frugalidade, a modéstia, a paternidade, entre outras coisas. Se conseguiu ou não estará ao gosto do freguês. Para o público acadêmico interessado na historiografia colonial e na trajetória dos principais atores políticos em questão - que é o nosso caso - pareceu um desperdício de esforços e páginas.

No entanto, é oportuno pontuar que, nem isso e tampouco o caráter 
essencialmente ideológico que constrói não uma ou outra parte do texto, mas sim que se ergue como a premissa que organiza o argumento da biografia, enfraquecem a força analítica e o rigor metodológico de Walter Isaacson. Tratase do que há de melhor na elaboração propagandística dos Estados Unidos como nação ainda dominante - e que acaba por, ainda que de maneiras distintas, reafirmar seu domínio cultural em meio às transformações que o capitalismo dinamiza. Seu trabalho tem substância, tem uma ideia própria, tem um argumento sólido, tem a capacidade de comoção, associa um personagem clássico a um movimento relativamente novo, situando, como abrimos este texto propondo, a própria figura de Benjamin Franklin, um self-made man dos tempos gráficos num pensador prático pronto para lidar com as novidades do mercado atual. Faz todo sentido, a partir do argumento de Isaacson, a linha de continuidade entre Franklin e Jobs. O mundo virtual da produção propagandística de um modo de vida supera do ponto de vista lógico o anterior, material e gráfico. No entanto, seu cerne e sua substância permanecem homogêneas: é ainda a própria ideologia do capitalismo meritocrático que vigora com carisma, heroísmo e manipulação.

$\mathrm{Na}$ síntese que apresenta em seu epílogo, que é, antes de mais nada, uma eloquente defesa da memória de Ben Franklin, Isaacson afirma: "as raízes de grande parte do que distingue essa nação podem ser encontradas em Franklin" (p.495). Trata-se de um receituário ideológico: humor, sabedoria, empreendedorismo nas inovações tecnológicas, tolerância amparando uma pluralidade religiosa, uma valorização das classes médias e, fundamentalmente: "individualismo e cooperação comunitária; pragmatismo filosófico; celebração da mobilidade meritocrática, o traço idealista arraigado em sua política externa; e as virtudes da Rua Principal que servem de alicerce para seus valores cívicos" (p.495).

A ótima biografia de Benjamin Franklin escrita por Walter Isaacson é, portanto, uma grande propaganda ideológica em favor de valores estadunidenses em nosso tempo. No entanto, diferente das cartilhas do Pobre Ricardo, ou dos best-seller de autoajuda destes tempos que entopem as prateleiras das maiores livrarias do país, é uma obra de requinte e talento, de um intelectual de ponta, com contundência e calibre para comover mentes.

Resenha recebida em novembro de 2016. Aceito em janeiro de 2016 